\title{
European Reference Network For Rare Vascular Diseases (VASCERN) Outcome Measures For Hereditary Haemorrhagic Telangiectasia (HHT)
}

\author{
Claire L. Shovlin ${ }^{1,2^{*}}$ (D), Elisabetta Buscarini ${ }^{3^{*}}$, Anette D. Kjeldsen ${ }^{4}$, Hans Jurgen Mager ${ }^{5}$, Carlo Sabba ${ }^{6}$, Freya Droege ${ }^{7}$,
} Urban Geisthoff ${ }^{7,11}$, Sara Ugolini ${ }^{8}$ and Sophie Dupuis-Girod ${ }^{9,10^{*}}$

\begin{abstract}
Hereditary haemorrhagic telangiectasia $(H H T)$ is a multisystemic vascular dysplasia that leads to nosebleeds, anaemia due to blood loss, and arteriovenous malformations (AVMs) in organs such as the lungs, liver and brain. HHT is estimated to affect 85,000 European citizens, but most health care providers have limited prior HHT exposure or training. Outcome Measures were developed and implemented by the HHT Working Group of the European Reference Network for Rare Vascular Diseases (VASCERN), in order to maximise the number of patients receiving good care. The measures specifically target areas where optimal management reduces morbidity and mortality in HHT patients, and were designed to be robust to emerging new evidence. Thresholds are the percentage of patients in particular settings who have been recommended screening, or provided with written advice. The 5 Outcome Measures cover (1) pulmonary AVM screening; (2) written nosebleed advice, (3) assessment of iron deficiency; (4) antibiotic prophylaxis prior to dental and surgical procedures for patients with pulmonary AVMs, and (5) written advice on pregnancy. They are not a blueprint for detailed HHT management, but are suitable for all clinicians to be aware of and implement. In summary, these 5 Outcome Measures provide metrics to identify healthcare providers of good care, and encourage care improvement by all healthcare providers.
\end{abstract}

Keywords: Anaemia, Antibiotic prophylaxis, Epistaxis, Iron deficiency, Nosebleeds, Pulmonary arteriovenous malformations, Pregnancy

\section{Background}

Development and implementation of Outcomes Measures are an effective part of Quality and Safety Frameworks that lead to Service Improvements. More specifically, if the Outcome Measures are carefully selected, their dissemination and implementation can directly improve patient care, including that from health care providers

\footnotetext{
*Correspondence: c.shovlin@imperial.ac.uk; elisabetta.buscarini@asst-crema.it; sophie.dupuis-girod@chu-lyon.fr

1 Respiratory Medicine, and VASCERN HHT European Reference Centre, Hammersmith Hospital, Imperial College Healthcare NHS Trust, London, UK ${ }^{3}$ Gastroenterology Department and VASCERN HHT European Reference Centre, Maggiore Hospital, ASST Crema, Crema, Italy

${ }^{9}$ Hospices Civils de Lyon, Hôpital Femme-Mère-Enfants, Service de Génétique, and VASCERN HHT European Reference Centre/ centre de Référence pour la maladie de Rendu-Osler, F-69677 Bron, France

Full list of author information is available at the end of the article
}

with limited prior exposure or training on the specific disease. Therefore simple, clinical practice-based Outcome Measures are particularly important for rare multisystemic conditions.

The current statement refers to one specific rare disease, hereditary haemorrhagic telangiectasia (HHT; Online Mendelian Inheritance in $\mathrm{Man}^{\circ}$ \#187300), which is a multisystemic vascular dysplasia that leads to telangiectasia and arteriovenous malformations (AVMs) in visceral and mucocutanous vascular beds [1]. Based on a conservative population prevalence of 1 in 6000 [2-4], HHT is estimated to affect approximately 85,000 European citizens. The main goal of management is to maximise the number of affected individuals receiving safe and effective preventative strategies in order to limit the number and severity of HHT complications. The reason this is

(c) The Author(s). 2018 Open Access This article is distributed under the terms of the Creative Commons Attribution 4.0 International License (http://creativecommons.org/licenses/by/4.0/), which permits unrestricted use, distribution, and 
important, is that where optimal management is instituted, previously reduced life expectancy $[3,5-7]$ may improve to that of the general population, [8] early strokes, brain abscess, maternal deaths and migraines are prevented, [9-11] nosebleeds are reduced, [12-17] and patients receive timely treatments for iron deficiency anaemia and other complications.

HHT can be diagnosed either clinically using the Curaçao criteria [1] (Table 1), or through a molecular gene test. A patient with definite HHT will have at least 3 of the 4 Curaçao Criteria, or a pathogenic sequence variant in ENG, ACVRL1 or SMAD4. Identification of pulmonary arteriovenous malformations (PAVMs) is recommended for all HHT patients because PAVMs commonly cause preventable complications in asymptomatic patients $[18,19]$. Risk-benefit analyses in asymptomatic individuals are more complex for other AVMs where screening is more controversial [20], limited to specific subpopulations, or not recommended [21].

\section{Main text}

Outcome Measures have been embedded within the Operational Criteria of the new European Reference Networks (ERNs) for Rare Diseases [22]. The HHT Outcome Measures were developed and implemented by the HHT Working Group of the ERN for Rare Vascular Diseases (VASCERN), [23] in order to maximise the number of patients receiving good care. Details of how the topics were selected and developed into Outcome Measures are provided in the Additional file 1.

Following on from an established diagnosis of HHT or PAVMs, the outcome measure thresholds are the percentage of adult patients in particular settings who have been recommended screening, or provided with written advice (Table 2). These will be met easily by best practice in HHT centres of excellence, but may not be achieved in general specialty care. The current manuscript refers only to the principles of management- details of management lie outside of the scope of this manuscript.

Table 1 The Curaçao Criteria

\footnotetext{
1. Epistaxis: spontaneous, recurrent nose bleeds

2. Telangiectases: multiple, at characteristic sites (lips, oral cavity, fingers, nose)

3. Visceral lesions such as gastrointestinal telangiectasia (with or without bleeding); pulmonary AVM; hepatic AVM; cerebral AVM; spinal AVM

4. Family history: a first degree relative with $\mathrm{HHT}$ according to these criteria The HHT diagnosis is definite if 3 criteria are present, possible or suspected if 2 criteria are present, and unlikely if fewer than 2 criteria are present. A pathogenic (null) sequence variant in ENG, ACVRL1 or SMAD4 also defines definite clinical HHT according to current understanding. A negative HHT gene test does not exclude HHT unless the gene variant causing HHT has been identified in another affected family member
}

\section{Measure 1}

At least $90 \%$ of definite HHT patients will have a screen for pulmonary arteriovenous malformations (PAVMs)

As stated elsewhere $[18,19]$, all HHT patients should be offered a screen for PAVMs in adult life. The screen and subsequent management may require cross-specialist referral. Screening should be repeated after pregnancies. Where a childhood screening test has been performed, screening should be repeated after the patient is fully grown.

HHT-associated PAVMs affect approximately $50 \%$ of HHT patients i.e. 40,000 Europeans. Recent European data suggest that untreated, 6-8\% may develop a cerebral abscess (usually with fatal or life-changing consequences [24-26]), at least $10-12 \%$ an early ischaemic stroke, and $1 \%$ of pregnancies will result in maternal death. Diagnosed patients can benefit from stroke reduction strategies, particularly embolization therapy to obliterate PAVMs $[9,27,28]$, antibiotic prophylaxis to prevent cerebral and visceral abscesses from silent bacteraemia (see Measure 4), and pregnancy management associated with a statistically improved survival rate in the event of a life-threatening complication [10].

A PAVM screen should be considered in all adult HHT patients. However the $90 \%$ threshold takes into account the facts that not all HHT patients choose to take up the option of PAVM screening, and there may also be competing clinical circumstances which render the discussion of screening inappropriate at the time of the clinical review. Overall, the Outcome Measure ensures that the possibility of PAVMs is remembered and addressed for all HHT patients, irrespective of their presentation pattern.

\section{Measure 2}

At least $90 \%$ of definite HHT patients will have received nosebleed advice in writing

Nosebleeds (epistaxis) affect $>90 \%$ of HHT patients, may be the presenting symptom of HHT, but may not be volunteered by patients unless specifically asked. HHT nosebleeds often occur daily, lasting many minutes and even hours: It is poorly appreciated that severe recurrent HHT nosebleeds can generate acute haemodynamic compromise and/or chronic cardiac failure in addition to iron deficiency anaemia.

A nosebleed history is to be evaluated for all HHT patients. The $90 \%$ threshold for written advice takes into account the facts that not all HHT patients have nosebleeds at any given time, though these may develop in the future, and the information can be important for family members also affected by HHT.

Overall, this measure ensures that irrespective of the patient's presentation pattern, epistaxis is not overlooked, 
Table 2 HHT outcome measures

\begin{tabular}{|c|c|c|c|c|}
\hline & Target Population & Estimated cases in Europe & Measure & Target threshold \\
\hline Measure 1\} & \multirow{3}{*}{$\begin{array}{l}\text { All HHT- clinical or molecular } \\
\text { diagnosis }\end{array}$} & \multirow[t]{3}{*}{85,000} & Screen for pulmonary AVMs & $\geq 90 \%$ \\
\hline Measure 2$\}$ & & & Receive nosebleed advice in writing & $\geq 90 \%$ \\
\hline Measure 3$\}$ & & & Assessment of iron deficiency at each consultation & $\geq 70 \%$ \\
\hline Measure 4 & Pulmonary AVMs (+/- HHT $)$ & 196,000 & $\begin{array}{l}\text { Receive written advice on antibiotic prophylaxis } \\
\text { prior to dental and surgical procedures }\end{array}$ & $100 \%$ \\
\hline Measure 5 & $\begin{array}{l}\text { Pregnant women with pulmonary } \\
\text { AVMs }\left(+/-H H T^{a}\right)\end{array}$ & $\sim 1000$ & Receive written advice on PAVM/HHT pregnancies & $100 \%$ \\
\hline
\end{tabular}

Prevalence estimates assume a European population of 510,000,000 (196,000 with HHT or PAVMs), 100,000 females with HHT or PAVMs; and an average of 1.6

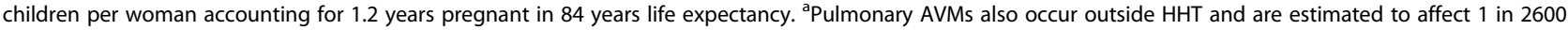
people [33]. HHT and non HHT-related pulmonary AVMs are currently managed in the same way

and practical information is provided to reduce the severity of epistaxis, and its sequelae.

\section{Measure 3}

At least $70 \%$ of definite HHT patients will have an assessment of iron deficiency at each consultation

Iron deficiency affects $>60 \%$ of all HHT patients (i.e. > 50,000 Europeans with HHT), and leads to anaemia (higher likelihood of blood transfusions), malaise, suboptimal immune, skeletal muscle and thyroid function; prematurity, poor maternal and perinatal outcomes in pregnancy; and impaired motor and cognitive development in children. In HHT patients, iron deficiency leads to angina and tachycardia, aggravates high output cardiac failure, and is associated with venous thromboemboli (VTE), and ischaemic strokes.

Generally, anaemia is defined by low haemoglobin, and iron deficiency is confirmed to be present when the ferritin is sub-normal [29, 30]. As stated elsewhere however [31], in $\mathrm{HHT}$, not all iron deficient patients have low haemoglobin since many patients have hypoxaemia due to pulmonary AVMs and need higher than normal haemoglobin to compensate. Similarly, a normal or high ferritin does not reliably exclude iron deficiency as it is an acute phase marker and may be supra-normal when serum iron, transferrin saturation index and red cell indices such as $\mathrm{MCV}$ or $\mathrm{MCH} /$ $\mathrm{MCHC}$ demonstrate iron deficient pictures [30].

Iron deficiency is commonly indolent and not appreciated by the patient until after correction. This measure ensures that irrespective of the patient's presentation pattern, iron deficiency is promptly identified, enabling optimal management.

\section{Measure 4}

$100 \%$ of patients with PAVMs will have written advice on antibiotics prior to dental and surgical procedures

This measure is recommended to reduce the rate of cerebral abscess which occurred in $6-8 \%$ of referrals to current European centres, usually resulting in substantial morbidity, and health care burdens [24-26]. Despite antibiotic prophylaxis being a long-standing recommendation for PAVM patients, in 2017, only $2 / 25$ (8\%) consecutive referrals to a UK centre for PAVM embolization had been advised to use prophylactic antibiotics.

The majority of cerebral abscesses in HHT/PAVM patients are associated with periodontal microbes, and/or precipitating dental and other interventional events that normally lead to transient bacteraemias, i.e. prior to non-sterile invasive procedures (such as dental, endoscopic, and surgical). In the general population, the bacteraemias are cleared (in terms of positive cultures) within minutes in the absence of antibiotics, but prevented or resolved earlier with prior antibiotic administration. [32] Good dental care is also important.

Written management advice to all PAVM patients is anticipated to ensure patients are aware and can communicate to all relevant practitioners, to address the current situation where patients may be refused prophylaxis and go on to develop a cerebral abscess [26].

\section{Measure 5}

$100 \%$ of pregnant women with PAVMs identified by CT scan/ imaging will be provided with written advice on PAVM/HHT pregnancies

Although the majority of PAVM pregnancies proceed normally, there is a $1 \%$ risk of maternal death in pregnancy that can be reduced by prior awareness. Precise content will vary by country according to obstetric care pathways but may include alerts regarding potential red flag symptoms demanding immediate hospital admission (haemoptysis, sudden acute breathlessness), antibiotic prophylaxis at delivery, and management as "high-risk" pregnancies involving a multiprofessional approach.

\section{Conclusion}

These five Outcome Measures provide metrics to identify healthcare providers of good care, encourage care improvement by all healthcare providers, and should be robust to emerging new evidence. They are not a blueprint for detailed HHT management, but are suitable for all clinicians to be aware of and implement. For the latest information, please see documents on the VASCERN website [23]. 


\section{Additional file}

Additional file 1: Methodological notes. (DOCX $28 \mathrm{~kb}$ )

\section{Abbreviations}

ACVRL 1: Gene encoding the ALK-1 protein; AVM(s): Arteriovenous malformation(s); ENG: Gene encoding the endoglin protein; ERNs: European Reference Networks; HHT: Hereditary haemorrhagic telangiectasia; PAVMs: Pulmonary arteriovenous malformations; SMAD4: Gene encoding the SMAD4 protein; VASCERN: European Reference Network for Rare Vascular Diseases

\section{Acknowledgements}

For helpful discussions, the authors are grateful to their colleagues in their VASCERN ERCs (particularly Fabio Pagella, Jens Kjeldsen, Kruthika Thangavelu, Elina Matti, Guido Manfredi, Patrizia Suppressa, Nicky Coote, and James Jackson; the VASCERN HHT ePAG patient group (particularly Claudia Crocione, Paolo Federici, Luisa Botella, and Christina Grabowski), and VASCERN (particularly Guillaume Jondeau, Marine Hurard and Natasha Barr).

\section{Availability of data and materials}

Data sharing not applicable to this article as no datasets were generated or analysed during the current study.

\section{Authors' contributions}

CLS, EB, ADK, JJM, CS, UG, and SDG developed the Outcome Measures; CLS wrote the first draft; CLS, EB, FD, ADK, JJM, CS, UG, SU, and SDG developed the discussions; all authors reviewed and approved the final manuscript.

\section{Authors' information}

CLS is the Chair, SDG is the CoChair and EB the Deputy CoChair of VASCERN HHT. The Outcome measures were developed by the HHT WG between March and June 2016. The discussion text was developed during monthly telecons, face to face meeting and by email October 2017-February 2018.

\section{Ethics approval and consent to participate}

Not applicable

\section{Consent for publication}

Not applicable

\section{Competing interests}

The authors declare that they have no competing interests.

\section{Publisher's Note}

Springer Nature remains neutral with regard to jurisdictional claims in published maps and institutional affiliations.

\footnotetext{
Author details

${ }^{1}$ Respiratory Medicine, and VASCERN HHT European Reference Centre, Hammersmith Hospital, Imperial College Healthcare NHS Trust, London, UK. ${ }^{2} \mathrm{NHLI}$ Vascular Science, Imperial College London, London, UK.

${ }^{3}$ Gastroenterology Department and VASCERN HHT European Reference Centre, Maggiore Hospital, ASST Crema, Crema, Italy. ${ }^{4}$ Department of Otorhinolaryngology and VASCERN HHT European Reference Centre, Odense University Hospital, University of Southern Denmark, Odense, Denmark. ${ }^{5}$ Department of Pulmonology and VASCERN HHT European Reference Centre, St. Antonius Hospital, Koekoekslaan 1, 3435 CM Nieuwegein, the Netherlands. ${ }^{6}$ Center for Rare Diseases, "Frugoni" Internal Medicine Unit, Interdepartmental HHT Center, Interdisciplinary Department of Medicine and VASCERN HHT European Reference Centre, University of Bari School of Medicine, Bari, Italy. ${ }^{7}$ Department of Otorhinolaryngology and VASCERN HHT European Reference Centre, Essen University Hospital, Essen, Germany. ${ }^{8}$ Department of Otorhinolaryngology and VASCERN HHT European Reference Centre, Fondazione Istituto di Ricovero e Cura a Carattere Scientifico (I.R.C.C.S) Policlinico San Matteo, University of Pavia, Pavia, Italy. ${ }^{9}$ Hospices Civils de Lyon, Hôpital Femme-Mère-Enfants, Service de Génétique, and VASCERN HHT European Reference Centre/ centre de Référence pour la maladie de Rendu-Osler, F-69677 Bron, France. ${ }^{10}$ Université de Lyon, Faculté de médecine, Université Lyon 1, F-69008 Lyon, France. ${ }^{11}$ Present address:
}

Department of Otorhinolaryngology, Head and Neck Surgery, University Hospital Marburg, Philipps-Universität Marburg, Marburg, Germany.

Received: 12 February 2018 Accepted: 20 June 2018

Published online: 15 August 2018

\section{References}

1. Shovlin $C L$, Guttmacher $A E$, Buscarini $E$, Faughnan ME, Hyland $R H$, Westermann CJ, Kjeldsen AD, Plauchu H. Diagnostic criteria for hereditary hemorrhagic telangiectasia (Rendu-Osler-weber syndrome). Am J Med Genet. 2000;91(1):66-7.

2. Bideau A, Plauchu H, Brunet G, Robert J. Epidemiological investigation of Rendu-Osler disease in France: its geographical distribution and prevalence. Population. 1989;44(1):3-22.

3. Kjeldsen AD, Vase P, Green A. Hereditary haemorrhagic telangiectasia: a population-based study of prevalence and mortality in Danish patients. J Intern Med. 1999;245(1):31-9.

4. Donaldson JW, McKeever TM, Hall IP, Hubbard RB, Fogarty AW. The UK prevalence of hereditary haemorrhagic telangiectasia and its association with sex, socioeconomic status and region of residence: a population-based study. Thorax. 2014;69(2):161-7

5. Sabbà C, Pasculli G, Suppressa P, D'Ovidio F, Lenato GM, Resta F, Assennato G, Guanti G. Life expectancy in patients with hereditary haemorrhagic telangiectasia. QJM. 2006:99(5):327-34

6. Donaldson JW, McKeever TM, Hall IP, Hubbard RB, Fogarty AW. Complications and mortality in hereditary hemorrhagic telangiectasia: a population-based study. Neurology. 2015;84(18):1886-93.

7. de Gussem EM, Edwards CP, Hosman AE, Westermann CJ, Snijder RJ, Faughnan ME, Mager JJ. Life expextancy of parents with hereditary Haemorrhagic telangiectasia. Orphanet J Rare Dis. 2016;11:46.

8. Kjeldsen A, Aagaard KS, Tørring PM, Möller S, Green A. 20-year follow-up study of Danish HHT patients-survival and causes of death. Orphanet J Rare Dis. 2016;11(1):157.

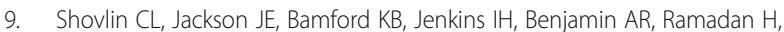
Kulinskaya E. Primary determinants of ischaemic stroke/brain abscess risks are independent of severity of pulmonary arteriovenous malformations in hereditary haemorrhagic telangiectasia. Thorax. 2008;63(3):259-66.

10. Shovlin CL, Sodhi V, McCarthy A, Lasjaunias P, Jackson JE, Sheppard MN Estimates of maternal risks of pregnancy for women with hereditary haemorrhagic telangiectasia (Osler-weber-Rendu syndrome): suggested approach for obstetric services. BJOG. 2008:115(9):1108-15.

11. Post MC, Thijs V, Schonewille WJ, Budts W, Snijder RJ, Plokker HW, Westermann CJ. Embolization of pulmonary arteriovenous malformations and decrease in prevalence of migraine. Neurology. 2006;66:202-5.

12. Hoag JB, Terry P, Mitchell S, Reh D, Merlo CA. An epistaxis severity score for hereditary hemorrhagic telangiectasia. Laryngoscope. 2010;120(4):838-43.

13. Gaillard $S$, Dupuis-Girod $S$, Boutitie $F$, Rivière $S$, Morinière $S$, Hatron PY, Manfredi G, Kaminsky P, Capitaine AL, Roy P, Gueyffier F, Plauchu H. ATERO study group. Tranexamic acid for epistaxis in hereditary hemorrhagic telangiectasia patients: a European cross-over controlled trial in a rare disease. J Thromb Haemost. 2014;12(9):1494-502.

14. Yaniv E, Preis M, Hadar T, Shvero J, Haddad M. Antiestrogen therapy for hereditary hemorrhagic telangiectasia: a double-blind placebo-controlled clinical trial. Laryngoscope. 2009:119(2):284-8.

15. Lund VJ, Darby Y, Rimmer J, Amin M, Husain S. Nasal closure for severe hereditary haemorrhagic telangiectasia in 100 patients. The Lund modification of the Young's procedure: a 22-year experience. Rhinology. 2017;55(2):135-41.

16. Shovlin $\mathrm{CL}$, Patel $\mathrm{T}$, Jackson JE. Embolisation of PAVMs reported to improve nosebleeds by a subgroup of patients with hereditary haemorrhagic telangiectasia. ERJ Open Res. 2016;2(2). eCollection 2016 Apr. PMID: 27730189.

17. Silva BM, Hosman AE, Devlin $\mathrm{HL}$, Shovlin CL. Lifestyle and dietary influences on nosebleed severity in hereditary hemorrhagic telangiectasia. Laryngoscope. 2013;123(5):1092-9.

18. Faughnan ME, Palda VA, Garcia-Tsao G, Geisthoff UW, McDonald J, et al. International guidelines for the diagnosis and management of hereditary haemorrhagic telangiectasia. J Med Genet. 2011;48:73-87.

19. Shovlin CL, Condliffe R, Donaldson JW, Kiely DG, Wort SJ, British Thoracic Society. British Thoracic Society Clinical Statement on Pulmonary Arteriovenous Malformations. Thorax. 2017;72(12):1154-63. 
20. Mohr JP, Parides MK, Stapf C, Moquete E, Moy CS, Overbey JR, Al-Shahi Salman R, Vicaut E, Young WL, Houdart E, Cordonnier C, Stefani MA, Hartmann A, von Kummer R, Biondi A, Berkefeld J, Klijn CJ, Harkness K, Libman R, Barreau X, Moskowitz AJ, International ARUBA investigators. Medical management with or without interventional therapy for unruptured brain arteriovenous malformations (ARUBA): a multicentre, non-blinded, randomised trial. Lancet. 2014;383(9917):614-21.

21. European Association for the Study of the Liver. EASL clinical practice guidelines: vascular diseases of the liver. J Hepatol. 2016;64(1):179-202.

22. European Reference Networks: https://ec.europa.eu/health/ern_en. Accessed 09 Feb 2018.

23. The European Reference Network for Vascular Diseases (VASCERN) HHT WG: https://vascern.eu/expertise/rare-diseases-wgs/hht-wg/ Accessed 09 Feb 2018.

24. Kjeldsen AD, Tørring PM, Nissen H, Andersen PE. Cerebral abscesses among Danish patients with hereditary haemorrhagic telangiectasia. Acta Neurol Scand. 2014;129(3):192-7.

25. Mathis S, Dupuis-Girod S, Plauchu H, Giroud M, Barroso B, Ly KH, Ingrand P, Gilbert B, Godenèche G, Neau JP. Cerebral abscesses in hereditary haemorrhagic telangiectasia: a clinical and microbiological evaluation. Clin Neurol Neurosurg. 2012;114(3):235-40.

26. Boother EJ, Brownlow S, Tighe HC, Bamford KB, Jackson JE, Shovlin CL. Cerebral abscess associated with odontogenic bacteremias, hypoxemia, and iron loading in immunocompetent patients with right-to-left shunting through pulmonary arteriovenous malformations. Clin Infect Dis. 2017; https://doi.org/10.1093/cid/cix373.

27. Lacombe P, Lacout A, Marcy PY, Binsse S, Sellier J, Bensalah M, Chinet T, Bourgault-Villada I, Blivet $\mathrm{S}$, Roume J, et al. Diagnosis and treatment of pulmonary arteriovenous malformations in hereditary hemorrhagic telangiectasia: an overview. Diagn Interv Imaging. 2013;94:835-48.

28. Woodward CS, Pyeritz RE, Chittams JL, Trerotola SO. Treated pulmonary arteriovenous malformations: patterns of persistence and associated retreatment success. Radiology. 2013;269:919-26.

29. NICE Clinical Knowledge Summaries (CKS):Treating iron deficiency anemia Available https://cks.nice.org.uk/anaemia-iron-deficiency\#!scenariorecommen dation Accessed 09 Feb 2018.

30. Iron Deficiency Anaemia. Assessment, Prevention, and control a guide for programme managers. World Health Organisation 2001. http://www.who. int/nutrition/publications/micronutrients/anaemia_iron_deficiency/WHO_ NHD_01.3/en/. Accessed 09 Feb 2018.

31. Rizvi A, Macedo P, Babawale L, Tighe HC, Hughes JMB, Jackson JE, Shovlin CL. Hemoglobin is a vital determinant of arterial oxygen content in hypoxemic patients with pulmonary arteriovenous malformations. Ann Am Thorac Soc. 2017:14(6):903-11.

32. Limeres Posse J, Álvarez Fernández M, Fernández Feijoo J, Medina Henríquez J, Lockhart PB, Chu VH, Diz Dios P. Intravenous amoxicillin/ clavulanate for the prevention of bacteraemia following dental procedures: a randomized clinical trial. J Antimicrob Chemother. 2016;71(7):2022-30.

33. Nakayama M, Nawa T, Chonan T, Endo K, Morikawa S, et al. Prevalence of pulmonary arteriovenous malformations as estimated by low-dose thoracic CT screening. Intern Med. 2012;51:1677-81.

Ready to submit your research? Choose BMC and benefit from:

- fast, convenient online submission

- thorough peer review by experienced researchers in your field

- rapid publication on acceptance

- support for research data, including large and complex data types

- gold Open Access which fosters wider collaboration and increased citations

- maximum visibility for your research: over $100 \mathrm{M}$ website views per year

At $\mathrm{BMC}$, research is always in progress.

Learn more biomedcentral.com/submissions 